\title{
Miíase primária em coelho doméstico causada por Lucilia eximia (Diptera: Calliphoridae) no Brasil: relato de caso
}

[Primary myiasis in a domestic rabbit caused by Lucilia eximia (Diptera: Calliphoridae) in Brazil: case report]

\author{
T.C. Moretti, P.J. Thyssen \\ Instituto de Biologia - UNICAMP \\ Caixa Postal 6109 \\ 13083-970 - Campinas, SP
}

\begin{abstract}
RESUMO
Relata-se a ocorrência de mí́ase primária em coelho doméstico Oryctolagus cuniculus (Lagomorpha: Leporidae) causada por Lucilia eximia (Diptera: Calliphoridae) em área urbana do município de Campinas, São Paulo.
\end{abstract}

Palavras-chave: coelho doméstico, miíase primária, Lucilia eximia

\begin{abstract}
The occurrence of primary myiasis in a domestic rabbit Oryctolagus cuniculus (Lagomorpha: Leporidae) caused by Lucilia eximia (Diptera: Calliphoridae) is reported in an urban area in the city of Campinas, São Paulo, Brazil.
\end{abstract}

Keywords: domestic rabbit, primary myiasis, Lucilia eximia, Brazil

\section{INTRODUÇÃO}

Miíase é a infestação de larvas de dípteros em tecidos de vertebrados vivos (Zumpt, 1965). Duas classificações são usadas para as miíases: primárias ou obrigatórias, cujas larvas desenvolvem-se sobre ou dentro do corpo de seu hospedeiro, e secundárias ou facultativas, cujas larvas desenvolvem-se normalmente em matéria orgânica em decomposição e, ocasionalmente, em tecido necrosado do hospedeiro vivo.

A família Calliphoridae é, ao lado dos dípteros oestróides, uma das mais importantes produtoras de mí́ases, apesar de poucos membros causarem miíase obrigatória (Guimarães e Papavero, 1999). Na região Neotropical, espécies dos gêneros Cochliomyia, Compsomyiops, Lucilia,
Calliphora e Chrysomya são as mais citadas como agentes causadores de miíases.

No gênero Lucilia são descritas 27 espécies. Lucilia eximia (Wiedemann, 1819) cujo hábito larval é saprófago, é vetora mecânica de patógenos de importância médico-veterinária. O adulto é atraído por grande variedade de substratos para alimentação e reprodução, tais como carcaças de animais e fezes humanas (Mendes e Linhares, 1993; Carvalho et al., 2000). A espécie é freqüentemente encontrada em áreas florestais e rurais no Brasil, Peru e Argentina (Ferreira, 1978; Linhares, 1981; Madeira et al., 1982; Baumgarter e Greenberg, 1984; Mariluis e Schnack, 1989).

No Brasil, há relatos de miíases por L. eximia em animais domésticos como em gatos (Madeira et

Recebido em 8 de julho de 2004 
al., 1989) e cães (Azeredo-Espin e Madeira, 1996), mas nenhum em coelho. Com relação ao coelho doméstico Oryctolagus cuniculus (Lagomorpha: Leporidae), há registros de miíases causadas por Cuterebra buccata, $C$. cuniculi, C. horripilum, C. lepivora (Diptera: Cuterebridae) (Jacobson et al., 1978), Lucilia sericata (Hinaidy e Niebauer, 1979; Meredith, 2003) e Cochliomyia hominivorax (Diptera: Calliphoridae) (Scott et al., 1996) nos Estados Unidos e Europa.

Neste relato, descreve-se o primeiro caso de mí́ase primária em um coelho doméstico $O$. cuniculus causada por L. eximia.

\section{CASUÍSTICA}

Descreve-se um caso de miíase primária em um coelho doméstico $O$. cuniculus causada por $L$. eximia. O animal adulto, do sexo masculino, de 36 meses de idade, peso de $4.100 \mathrm{~g}$, castrado, pelagem predominantemente cinza escura e curta, e descendente de cruzamento das linhagens Mini Lop e Fuzzy Lop Americano, foi mantido como único animal de estimação em uma residência da área urbana do município de Campinas, SP. Foram observadas mudanças de comportamento, incluindo certo grau de depressão e paresia, falta de apetite, alopecia, acúmulo de fezes e inchaço na região perianal. Ao exame clínico, observou-se, no local, um orifício de aproximadamente $0,8 \mathrm{~cm}$ de diâmetro. Nenhuma lesão prévia no animal fora notificada. Desse orifício foram removidas 14 larvas em terceiro estádio, presentes no tecido subcutâneo, as quais foram encaminhadas para identificação.

No laboratório, as larvas foram acondicionadas em pote plástico contendo fígado bovino cru e mantidas em câmara climática sob $27 \pm 1^{\circ} \mathrm{C}$ para completo desenvolvimento. Após 12 dias, indivíduos adultos emergiram e foram identificados, por meio de chave dicotômica (Dear, 1985), como L. eximia.

\section{DISCUSSÃO}

No Brasil, em geral, as miíases são consideradas comuns e de pouca importância, especialmente em animais domésticos (Cramer-Ribeiro et al., 2002).
Bovinos, caninos, suínos, caprinos, ovinos e eqüinos são as espécies mais freqüentemente identificadas como hospedeiras de miíases (Lello et al., 1982). Apesar da alta freqüência, as miíases não são de notificação obrigatória. Além disso, os inquéritos existentes sobre miíases no país ficam restritos a duas espécies: Dermatobia hominis (Diptera: Cuterebridae) e $C$. hominivorax. Em outros casos, durante a rotina veterinária, geralmente as larvas são retiradas e nem mesmo o agente causador é identificado (informação verbal ${ }^{1}$ ).

Lucilia eximia, normalmente encontrada em carcaça de animais, é uma das primeiras colonizadoras desse substrato, mesmo sob influência de predação e competição com outras espécies (Azeredo-Espin e Madeira, 1996). Prado e Guimarães (1982) relataram a probabilidade de deslocamento dessa espécie por moscas do gênero Chrysomya em algumas áreas do Brasil.

Há poucos relatos da espécie como produtora de miíase primária, por isso, é importante investigar seu comportamento não usual. Tais mudanças sugerem a ocupação ou a criação de um novo nicho que pode aumentar com a intensificação da domesticação de animais. É interessante ressaltar que mudanças de comportamento de espécies causadoras de miíases, inclusive aumento da área de ocupação, foram relatadas nos gêneros Lucilia, Oestrus, Hypoderma e Gasterophilus, tendo como principal causa a atividade humana (Hall e Wall, 1995).

Relatos de casos são fundamentais para a compreensão da biologia, ecologia e impacto econômico de dípteros produtores de miíases, possibilitando entender seus padrões de distribuição, sua flutuação populacional e suas relações filogenéticas.

\section{REFERÊNCIAS BIBLIOGRÁFICAS}

AZEREDO-ESPIN, A.M.L.; MADEIRA, N.G. Primary myiasis in dog caused by Phaenicia eximia (Diptera: Calliphoridae) and preliminary

\footnotetext{
1 Helena Marieta Ricci, Médica-veterinária da Clínica Veterinária Taquaral, Campinas, SP.
} 
mitochondrial DNA analysis of the species in Brazil. J. Med. Entomol., v.33, p.839-843, 1996.

BAUMGARTER, P.L.; GREENBERG, B. The genus Chrysomya (Diptera: Calliphoridae) in the New World. J. Med. Entomol., v.21, p.105-113, 1984.

CARVALHO, L.M.L.; THYSSEN, P.J.; LINHARES, A.X. et al. A checklist of arthropods associated with carrion and human corpses in southeastern Brazil. Mem. Inst. Oswaldo Cruz, v.95, p.135-138, 2000.

CRAMER-RIBEIRO，B.C.; SANAVRIA，A.; OLIVEIRA, M.Q. et al. Inquérito sobre os casos de míase por Cochliomyia hominivorax em cães da zona sul do município do Rio de Janeiro no ano 2000. Braz. J. Vet. Res. Anim. Sci., v.39, p.171-175, 2002.

DEAR, J.P. A revision of the New World Chrysomyini (Diptera: Calliphoridae). Rev. Bras. Zool., v.3, p.109-169, 1985.

FERREIRA, M.J.M. Sinantropia de dípteros muscoídeos de Curitiba, Paraná. I. Calliphoridae. Rev. Bras. Biol., v.38, p.445-454, 1978.

GUIMARÃES, J.H.; PAPAVERO, N. Myiasis in man and animals in the Neotropical region. São Paulo: PLÊIADE, 1999. 308p.

HALL, M.; WALL, R. Myiasis of humans and domestic animals. Adv. Parasitol., v.35, p.257334, 1995.

HINAIDY, H.K.; NIEBAUER, G.W. Fakultativmyiasis bei einem Kaninchen und einem Meerschweinchen. Wien. Tierärztl. Mschr., v.66, p.384-386, 1979.

JACOBSON, H.A.; MCGINNES, B.S.; CATTS, E.P. Bot fly myiasis of the cottontail rabbit, Sylvilagus floridanus mallurus in Virginia with some biology of the parasite, Cuterebra buccata. J. Wildl. Dis., v.14, p.56-66, 1978.

LELLO, E.; PINHEIRO, F.A.; NOCE, O.F. Epidemiologia de míases no município de
Botucatu, SP, Brasil. Arq. Esc. Vet. UFMG, v.34, p.93-108, 1982.

LINHARES, A.X. Synanthropy of Calliphoridae and Sarcophagidae (Diptera) in the city of Campinas, São Paulo, Brazil. Rev. Bras. Entomol., v.25, p.89-215, 1981.

MADEIRA, N.G.; DIAS, F.S.; MASCARENHAS, C.S. Contribuição ao conhecimento da fauna de Calliphoridae (Diptera) sinantrópicos de Pampulha, Belo Horizonte, Minas Gerais. Rev. Bras. Entomol. , v.26, p.137-140, 1982.

MADEIRA, N.G.; SILVEIRA, G.A.R.; PAVAN, $C$. The occurrence of primary myiasis in cats caused by Phaenicia eximia (Diptera: Calliphoridae). Mem. Inst. Oswaldo Cruz, v.84, p.341, 1989.

MARILUIS, J.C.; SCHNACK, J.A. Ecology of the blow flies of an eusynanthropic habitat near Buenos Aires (Diptera: Calliphoridae). Eos, v.65, p.93-101, 1989.

MENDES, J.; LINHARES, A.X. Atratividade por iscas e estágios de desenvolvimento ovariano em várias espécies sinantrópicas de Calliphoridae (Diptera). Rev. Bras. Entomol., v.37, p.157-166, 1993.

MEREDITH, A. Skin diseases of rabbits. Ir. Vet. J., v.56, p.52-56, 2003.

PRADO, A.P.; GUIMARÃES, J.H. Estado atual de dispersão e distribuição do gênero Chrysomya Robineau- Desvoidy na região Neotropical (Diptera: Calliphoridae). Rev. Bras. Entomol., v.26, p.225-231, 1982.

SCOTT, D.W.; MILLER, W.H.; GRIFFIN, C.E. Muller \& Kirk, small animal dermatology. Philadelphia: W.B. Saunders, 1996. 1520p.

ZUMPT, F. Myiasis in man and animals in the Old World. London: Butterworths, 1965. 267p. 